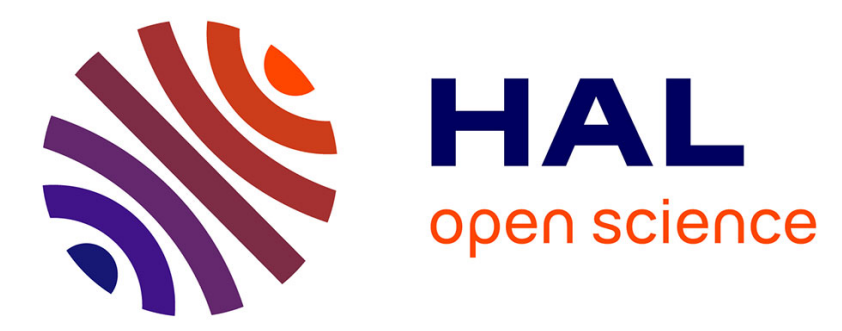

\title{
Can an early mathematical intervention boost the progress of children in kindergarten? A field experiment
}

\author{
Céline Darnon, Michel Fayol
}

\section{To cite this version:}

Céline Darnon, Michel Fayol. Can an early mathematical intervention boost the progress of children in kindergarten? A field experiment. European Journal of Psychology of Education, 2022, 37, pp.1-18. 10.1007/s10212-021-00550-4 . hal-03395896

\section{HAL Id: hal-03395896 \\ https://hal.science/hal-03395896}

Submitted on 25 Oct 2021

HAL is a multi-disciplinary open access archive for the deposit and dissemination of scientific research documents, whether they are published or not. The documents may come from teaching and research institutions in France or abroad, or from public or private research centers.
L'archive ouverte pluridisciplinaire HAL, est destinée au dépôt et à la diffusion de documents scientifiques de niveau recherche, publiés ou non, émanant des établissements d'enseignement et de recherche français ou étrangers, des laboratoires publics ou privés. 
AN EARLY MATHEMATICAL INTERVENTION

\title{
Can an Early Mathematical Intervention Boost the Progress of Children in Kindergarten? A Field Experiment
}

\author{
Céline Darnon \\ Michel Fayol \\ Université Clermont Auvergne, LAPSCO - CNRS UMR6024
}

Authors' note

Céline Darnon \& Michel Fayol, Laboratoire de Psychologie Cognitive et Sociale, LAPSCO(UMR6024), CNRS, Université Clermont Auvergne. This research was supported by a Convention from the Ministère de l'Education Nationale (MEN, APPMATHSMAT). We wish to thank Cécile Compeau, Caroline Ravizy, Emmanuelle Neuville \& Claire Migne for their involvement in data collection. We also wish to thank Corine Sancier, Christine Fournet-Fayas and all the teachers who collaborated on this project. Their commitment was highly appreciated. The authors declare that there are no potential conflicts of interest with respect to the research, authorship, and/or publication of this article. Data of the present study are openly available on: osf.io/ktp4v. Correspondance should be adressed to Céline Darnon, Laboratoire de Psychologie Cognitive et Sociale, LAPSCO, UMR6024, CNRS, Université Clermont Auvergne, 34 Avenue Carnot, 63037 Clermont-Ferrand Cedex, France (celine.darnon@uca.fr). https://orcid.org/0000-0003-2613-689X. 


\begin{abstract}
Socioeconomic status (SES) has been shown to be associated to children's arithmetic knowledge as early as kindergarten, which is an important issue, given that early numeracy knowledge and skills usually correlate to later academic achievement in arithmetic. In line with recent research, it is argued that the regular practice of exercises involving cardinality and arithmetic transformations during class time could accelerate the progress of children, particularly among low-SES children. Participants were 118 kindergarteners $\left(M_{a g e}=3.87\right)$. Teachers were randomly assigned to the intervention group (immediate implementation of the intervention; $\mathrm{N}=64$ ) or the control group (intervention delayed, $\mathrm{N}=54$ ). This intervention consisted of playful exercises involving quantities and numerical transformations. The results indicated that the intervention tended to accelerate progress on the verbal numerical sequence, particularly among lower-SES children. In addition, the intervention tended to accelerate progress on cardinality and arithmetic. These results provide preliminary evidence of the effectiveness of the intervention to help children acquire basic mathematical skills.
\end{abstract}

Keywords. Mathematics, Early intervention, Socioeconomic status, Kindergarten 


\section{Can an Early Mathematical Intervention Boost the Progress of Children in Kindergarten? A Field Experiment}

Children who enter elementary school differ widely in number knowledge, which can have important consequences for their future. Indeed, early numeracy knowledge and skills are usually related to later academic achievement in arithmetic (Arnold \& Doctoroff, 2003; Duncan et al., 2007; Pagani et al., 2010).

Mathematical abilities are acquired before and outside of school, notably through activities and interactions at home (e.g., playing board and card games, cooking, and shopping; Ginsburg, 1977; Lefevre et al., 2010). Consequently, significant individual differences exist between the extent and quality of children's numeracy experience before entering preschool. Research has documented that these differences are, to a large extent, driven by differences in income, cultural practice, and time devoted by parents to their kids (Blevins-Knabe \& Musun-Miller, 1996; Lefevre et al., 2009; 2010; Levine et al., 2010; Melhuish et al., 2008). For example, middle-class mothers generally engage their children in more complex numerical activities than working-class mothers (Saxe et al., 1987), and these supportive activities (e.g., labeling the quantities of sets of objects) are related to children's subsequent math achievement (Casey et al., 2018). Thus, as early as kindergarten, children from low-SES families usually exhibit lower performance in mathematics and progress at a slower rate than their higher-SES counterparts (Jordan et al., 2009; Stipek \& Ryan, 1997).

However, recent research has suggested that early numeracy interventions could significantly improve children's mathematical performance and, in many cases, prove particularly efficient for low SES children (e.g., Raudenbush et al., 2020). The purpose of the present experiment is to design and test the effects of such an intervention on the development of three key mathematics abilities: Verbal numerical sequence, cardinality and arithmetic 
transformation; three mathematical abilities that are key at the kindergarten age and particularly predictive of future mathematical achievement (Fayol, 2018).

\section{Can Mathematical Skills be Trained?}

According to previous research, the number competencies can be significantly improved through relevant interventions in preschool settings (e.g., Clements et al., 2020; Frye et al., 2013; Lilliard \& Else-Quest, 2006; Siegler \& Ramani, 2008; for a recent meta-analysis, see Nelson \& McMaster, 2019). For example, Lewis Presser, Clements, Ginsburg, and Ertle (2015) found that kindergarteners who followed a specific mathematics curriculum ("Big Math for Little Kids") progressed to a greater extent than children in business-as-usual conditions. In the same vein, Clement and Sarama (2008) demonstrated that a targeted preschool mathematics program built on scientific knowledge ("building blocks") increased mathematical performance when compared to control groups. Clément (1984) also showed that sequences based on logical foundations (classification and seriation) or number skills (counting) enhanced preschool children's mathematical abilities (counting and logical operations). Other research has similarly documented that specific training programs could significantly increase preschool children's numerical performance (Passolunghi \& Costa, 2016; Kyttälä et al., 2015).

Moreover, authors in the field point to the fact that these interventions prove particularly efficient to increase low-SES children's mathematical performance (Jordan \& Levine, 2009; Siegler, 2009; Stipek \& Ryan, 1997). For example, Schacter et al. (2016) showed that a 6-week tablet intervention ("Math Shelf") increased low-income preschoolers' mathematics knowledge. In the same vein, Jordan et al. (2012) found that a small-group number sense intervention could increase specifically low-income students' mathematical performance and Siegler and colleagues (Siegler \& Ramani, 2009; Siegler \& Ramani, 2008) documented that preschool children, particularly low-income children, improved their 
numerical knowledge by playing linear number board games. Similarly, Starkey and Klein (2000) randomly assigned Head Start families to an intervention or control condition. Preschool teachers provided low-income families with a series of home-conducted math activities involving parent/child dyads. Children whose parents were assigned to the intervention group progressed more in terms of their mathematical knowledge than those in the control group. Starkey, Klein, and Wakeley (2004) extended this work to preschools. Using a pretest/intervention/posttest design covering large domains of mathematics (i.e., arithmetic, space, geometry, measurement), they provided children (4-year-olds) from lowand middle-income families with both classroom and home activities. At the end of the intervention program, the scores of the low-income children who received the intervention had increased more than those of their middle-income counterparts.

These studies provide encouraging results about the possibility of increasing low SES children skills in mathematics by implementing specific interventions before children enter elementary school. However, these studies do not always compare low-SES students to higher-SES students. Moreover, although some studies focused on specific abilities, most of them examined broad mathematics concepts and skills, making difficult to determine which of the specific abilities should be targeted in early interventions. Consequently, more research is needed to determine which mathematical skills should be targeted in preschool in order to benefit all children and, in particular, low-SES children (i.e., those who are least likely to work on these abilities at home). The present research focuses on two key abilities: cardinality (i.e., the capacity to identify small sets and decide about their equivalence) and arithmetic transformation (i.e., the capacity to detect changes in small sets of items).

\section{Two Key Abilities at the Kindergarten Age}

The present intervention focuses on two abilities that develop particularly at this age, and which are significantly related to later arithmetic skills (Benoit et al., 2013; Lefevre et al., 
2010): cardinality and arithmetic transformation. Cardinality is a highly abstract concept, consisting of, for example, understanding that 3 is the property that all sets with three elements have in common (i.e., the "three-ness"), regardless of their empirical, spatial, and temporal characteristics (Wiese, 2003). A gradual progression in understanding the cardinal equivalence between sets without counting or verbalizing takes place between 3 and 4 years of age (see Mix et al., 2002). Subitizing (i.e., recognizing the total number of a set without counting the number of items, Starkey \& Cooper, 1995) develops in a step-by-step manner (Condry \& Spelke, 2008; Le Corre et al., 2006; Sarnecka \& Carey, 2008) and is related to later acquisitions of counting and other arithmetic skills (Benoit et al., 2013; Lefevre et al., 2010). Finally, the "count-cardinal concept" (Fuson, 1988), which refers to understanding that the last number named when counting a collection of items indicates the number of objects in this collection, is first discovered with small numbers and later generalized to larger numbers (Sarnecka \& Carey, 2008). That means that children first recognize and name small quantities, ranging from 1 to 3 or 4 , without having to count them. Learning the names of these groups occurs very gradually, following the order from one (around $2^{1 / 2}$ years) then two, three, and finally four (around 4 or $4 \frac{1}{2}$ years). Later on, they understand the principle of cardinality and, although not simultaneously, the principle of iteration of the unit (i.e., the successor principle; Davidson et al., 2012), which means that any addition of an element to a collection comprising $n$ elements results in an advance of one in the verbal numerical chain $(n+1)$ and vice versa. It is worth noting that the development of cardinality is related to the development of ordinality (i.e., capacity to decide about the most basic relationship, meaning that one set is greater than another; Lyons et al., 2016). Ordinality also develops gradually and perhaps as a consequence of cardinality (e.g., Colomé \& Noël, 2002; Knudsen et al., 2015) and is also associated with arithmetic performance (Lyons \& Beilock, 2011; Lyons et al., 2014; Sasanguie \& Vos, 2018). 
Both cardinality and ordinality are involved in arithmetic transformations. From 2 to 3 years of age onward, children understand the direction of quantity modifications - namely, adding (versus removing) an element leads to an increase (versus a decrease) in magnitude, including discrete as well as continuous aspects (Vilette, 2002). Understanding arithmetic transformations and becoming able to provide the exact results of numerical modifications depends on age and quantity size. For example, Huttenlocher et al. (1994) reported that 3:9- to 3:11-year-old children are very accurate when solving small additions (e.g., 97\% for $1+1$ ) but less efficient with $2+1(70 \%)$ and weaker with $3+1(40 \%)$ and $3+2(27 \%)$. Moreover, problem situations are much more successfully processed when story problems are presented in a nonverbal rather than verbal format, especially for low-SES children (Jordan et al., 1992; Levine et al., 1992). Indeed, although lower- and higher-SES kindergarten children performed equally on a nonverbal tasks, lower-income children performed more poorly than middleincome children on verbal tasks (Jordan et al. 1992), and the gap between the two income groups were still evident with story problems even after a year of instruction (Jordan et al., 1994). At a very early age, children process problem situations using iconic mental models that allow them to figure out situations and operate on them using diverse strategies (e.g., rote counting, separating sets, using fingers; Siegler \& Shrager, 1984). Later, and particularly when they come from privileged families, children are better at processing verbal information and using verbal strategies (Rasmussen \& Bisanz, 2005).

To summarize, the research reviewed above shows that cardinality and arithmetic transformations are two key abilities that are particularly under development in kindergartens (Chu et al., 2015; Fayol, 2018; Geary \& van Marle, 2018). In addition, these are two abilities on which gaps are likely to appear between pupils of high and low socio-economic status. Therefore, the intervention we tested in the present research specifically targeted these two skills. 


\section{Overview and Hypotheses}

The purpose of the present research was to test the effects of an early intervention, based on the regular practice of exercises involving cardinality, ordinality, and transformations, among 3- to 5-year-old children. We argue that this intervention should facilitate quantity processing and number acquisition for all children, but more so for low-SES children. To test this hypothesis, teachers were trained in these basic mathematical concepts. Half of the teachers were then randomly assigned to either the intervention group (for which the implementation of the intervention was immediate) or the control group (for which it was delayed). The children's mathematical skills (i.e., verbal numerical sequence, cardinality, and arithmetic) were tested before and after the implementation of the intervention. All the children were expected to progress between the pre- and the posttest, but this progress was expected to be stronger for the intervention group than for the control group (main effect of the intervention on progress). In addition, the positive effect of the intervention should be stronger for lowSES children than for high-SES children (intervention x SES interaction).

\section{Method}

\section{Participants}

A priori power analyses indicated that a sample of about 96 participants was required to have an $80 \%$ chance of detecting a small interaction $\left(\eta_{\mathrm{p}}{ }^{2}=.03\right)$ between 2 between-subjects variables (SES and intervention) and a within-subject variable (pre-/posttest) at a $p$ level of .05 . Because all the children present during class time were included, a total sample of 125 pupils from 18 different classes participated in the experiment. Parents' occupations were unknown for six participants, and one participant had an insufficient level of language; these seven participants were removed from the sample. Thus, the final sample consisted of 118 participants $\left(M_{\text {age }}=3.87\right.$ years old): 62 boys and 56 girls. Fifty-seven pupils were in their first year of kindergarten while the remaining 61 were their second year of kindergarten. Classes 
(and their respective teachers) were randomly assigned to the intervention condition $(n=64)$ or the control group $(n=54)$. Information on parental occupations was obtained from the school administration. Children who had one or both parents with an occupation level equal to or greater than 47 ("technician") on the INSEE classification were coded as "high-SES" ( $n=$ 79). The others were coded as "low-SES" children $(n=39$; for a similar categorization, see [Authors], 2013). Sample size per condition and SES are reported in Table 1. It is worth noting that children were nested within classrooms. However, both the number of classes (N $=5$ in first year; $\mathrm{N}=8$ in second year; 5 classes included both years within the same class) and the number of participants per classes (between 6 and 27) were too small to conduct multi-level analyses (Maas \& Hox, 2005).

\section{Overview of the Procedure}

The pupils took the mathematical tests twice: an initial pretest in the fall semester (November and December) and a second posttest in the spring semester (March and April). The teachers who volunteered to participate in this research program, as part of their mandatory training in numeracy, all followed an 8-week numeracy training program during the fall semester that consisted of a 2-hour presentation followed by 5 workshops led by one of the authors. This training was mainly theoretical. After the fourth workshop, the teachers (who appeared to be all women) were randomly assigned to one or the other of the experimental conditions: half of the teachers implemented the intervention in January, under the guidance of the researchers, whereas the others implemented the intervention in April (after the posttest session). The teachers in this second group (i.e., the control group) agreed not to make any changes to their usual practices before the posttest session ("business as usual"). Thus, children in the control group did some regular mathematic exercises every day, but these exercises were not standardized and corresponded to what the teachers did before receiving the numeracy training program. The fifth workshop session, which took place in December for the 
experimental group and April for the control group, was a practical session. In this session, the final content and material of the intervention were presented and discussed with the teachers. At the end of this session, individual discussion took place so that the researchers could check the teachers all knew how to implement the intervention and were all committed to following it as closely as possible. It is worth noting that two additional short sessions involving both the teachers and the researchers were organized two weeks after the beginning of the experiment and then at the end of the intervention period so that researchers could answer any questions and make sure teachers followed the protocol without difficulties.

\section{Intervention}

The content of the intervention was established during the final workshop as a result of the close collaboration between teachers and researchers. It consisted of playful exercises designed to encourage pupils to engage in various activities involving the treatment of the cardinal and ordinal dimensions of quantities while also performing the physical and mental manipulation (i.e., transformations) of these quantities. These exercises followed a learning progression. Indeed, teachers had children first worked on how-many tasks (count-cardinal concept) and the give-n tasks (cardinal-count concept) before doing exercises on arithmetical transformations. In additions, they made sure each number was correctly mastered before introducing new numbers. Examples of activities and pictures are provided on OSF (https://osf.io/ktp4v/). The intervention took place over five consecutive weeks and consisted of brief 15-minute sessions on four days per week in small groups of 4 to 7 pupils. The intervention materials selected by the teachers included a bear family (from 2 to 4 characters in the first year; from 4 to 6 in the second year). The collections and transformations were constructed using plates and forks, seats in a bear car, gardening equipment, etc. The quantities treated were either 1,2 , or 3 for the first year or 3, 4, and 5 for the second year. The pupils were asked to manipulate the objects and associate them with each character by 
creating sets of equivalent cardinalities. The teachers presented situations (e.g., the bear family goes on a picnic) in which either some objects were missing (and children had to identify and search for in exact numbers, possibly using term-to-term correspondence) or too many entities were present (e.g., a 4-seat car for a family of 3). New characters would sometimes arrive or leave, forcing the children to make adjustments to the various quantities. In addition, the members of each bear family were of different sizes, making it possible to focus on the order of their sizes and the size of the objects associated with them (e.g., bed, cutlery, bicycles). The week's activities were organized in a flexible way. However, more time was devoted to the treatment of cardinality, with the aim of confronting the children with collections of various shapes, colors, and sizes in order to induce a progressively more abstract conception of cardinality. As the sessions progressed, the children were asked to introduce one or more new characters, resulting in the subsequent transformation of the associated objects.

\section{Measures}

The children were tested twice during school hours in their respective schools: first in the fall semester (pretest session), and then in the spring semester (posttest session). Three main dimensions of numerical abilities were assessed: the mastery of the verbal numerical sequence, cardinality, and arithmetic. The tests were taken from [Authors] (2017) and the full set of tests is provided on the OSF (https://osf.io/ktp4v/). The tests were conducted individually. Although all the children took the same tests, the numbers presented varied depending on the preschool level (first versus second year).

\section{Verbal numerical sequence}

Two questions were used to evaluate the children's mastery of the verbal numerical sequence. First, the children were asked to count as far as they could. The final score was the highest number the children reached without making a mistake. This score ranged from 0 to 59 during 
the pretest $(M=10.669 ; S D=10.712)$ and from 0 to 70 during the posttest $(M=17.607 ; S D=$ 14.067). Second, in order to measure the breakable chain level of counting (Fuson, 1988), the participants were asked to count from 3 (for first year) or 4 (for second year). If the children succeeded, they received a score of 1 ( $n=53$ at pretest; $n=66$ at posttest); if they failed, they received a score of 0 ( $n=65$ at pretest; $n=52$ at posttest).

\section{Cardinality}

Three tests assessed children's mastery of cardinality: cardinality in designation (the "how many" task) and production (the "give $n$ " task) and the term-to-term correspondence with fingers.

The "How Many" Task. The children were asked to indicate how many pieces of fruit were in a box. Children in the first year responded to 5 items (the actual answers were, respectively, 3, 1, 4, 2, and 3 again) while children in the second year responded to 7 items (the same items as the first year plus 2 more items, for which the actual answers were, respectively, 5 and 6). The mean performance of children could range from 0 to 5 and 0 to 7 in the first and second year, respectively. To allow for comparisons, all children's scores were transformed into a score on a scale of $10(M=7.349 ; S D=2.864$ at pretest; $M=8.441 ; S D=$ 2.427 at posttest).

The "Give N" Task. The participants were then asked to put $n$ pieces of fruit in a box (from 1 to 4 for the first year and from 1 to 6 for the second year). Children in the first year responded to 5 items and those in the second year responded to 7 . These scores were also transformed into a score on a scale of $10(M=6.056 ; S D=2.643$ for pretest, $M=7.378 ; S D=$ 2.455 for posttest).

Term-to-Term Correspondence. A fixed quantity of pieces of fruit was shown to each child, who was prompted: "Show me on your fingers how many pieces of fruit there are in the box." Children in the first year responded to 3 items ( 2 bananas, 3 strawberries, 4 apples) 
whereas those in the second year responded to the same 3 items plus another one ( 5 strawberries). The score corresponded to the number of correct answers. Again, as children in the first year answered 3 items and those in the second year answered 4, the scores were transformed into a score on a scale of $10(M=6.751 ; S D=3.692$ for pretest, $M=8.369 ; S D=$ 2.939 for posttest).

\section{Arithmetic}

The arithmetic test contained two transformation questions and a comparison question. In the first step, the experimenter removed an item of fruit from the box and asked how many pieces of fruit were left in the box. The children could see the contents of the box before but not after the item was removed. The experimenter then added an item of fruit to the contents of the box. Finally, the experimenter showed the children two boxes - one with 1 item and one with 3 items - and asked the children what they would have to do in order to have the same number of items in each of the two boxes (comparison item). One point was awarded for each item successfully solved. Thus, the arithmetic score could range from 0 to $3(M=1.822 ; S D=$ 0.949 for pretest; $M=2.178 ; S D=0.912$ for posttest $)^{3}$

\section{Overview of the Analyses}

An improvement index was computed for each dependent variable by subtracting the score obtained on the pretest from the score obtained on the posttest. Consequently, a positive (versus negative) score indicated the amount of improvement (versus regression) the children had made between the pre- and posttest; a score of 0 indicated that their performance remained the same. Descriptive statistics on each of the dependent variables are presented in Table 1.

An ANOVA with 2 between-subjects variables (SES: low versus high; condition: intervention versus control) was conducted on the relative improvement scores. For all dependent variables, a main effect of intervention and an interaction between SES and the 
intervention condition were expected. Level (first versus second year) was also entered in the analyses as a control variable. However, as this variable was only a control variable and because potential 3-way interactions were based on very small sample sizes $(5<n<27)$, only the main effects and 2-way interactions will be discussed further.

\section{Results}

\section{Verbal Numerical Sequence}

\section{Counting as Far as Possible}

The main effect of the intervention was not significant: $F(1,109)=1.497, p=.224 ; \eta_{p}{ }^{2}=.014$. The expected interaction between intervention and SES was not significant, but marginal, $F(1,109)=2.782, p=.098, \eta_{p}^{2}=.025,[-.13 .84,1.19]$ (numbers in brackets represent $95 \%$ CIs), as represented in Figure 1. Simple slopes indicated that the effect of the intervention was marginal for lower-SES children, $t(109)=1.753, p=.082$, but not for higher-SES children, $t(109)<1$. The interaction between SES and level was also not significant but marginal: $F(1$, $109)=3.110, p=.081, \eta_{p}{ }^{2}=.028[-0.83,14.2]$. The intervention condition tended to result in greater improvement than the control condition in the first year, $t(109)=1.694, p=.093$, but not in the second year, $t(109)<1$. None of the other effects reached significance, with all $F \mathrm{~s}<$ $2.79, p>.10$. 


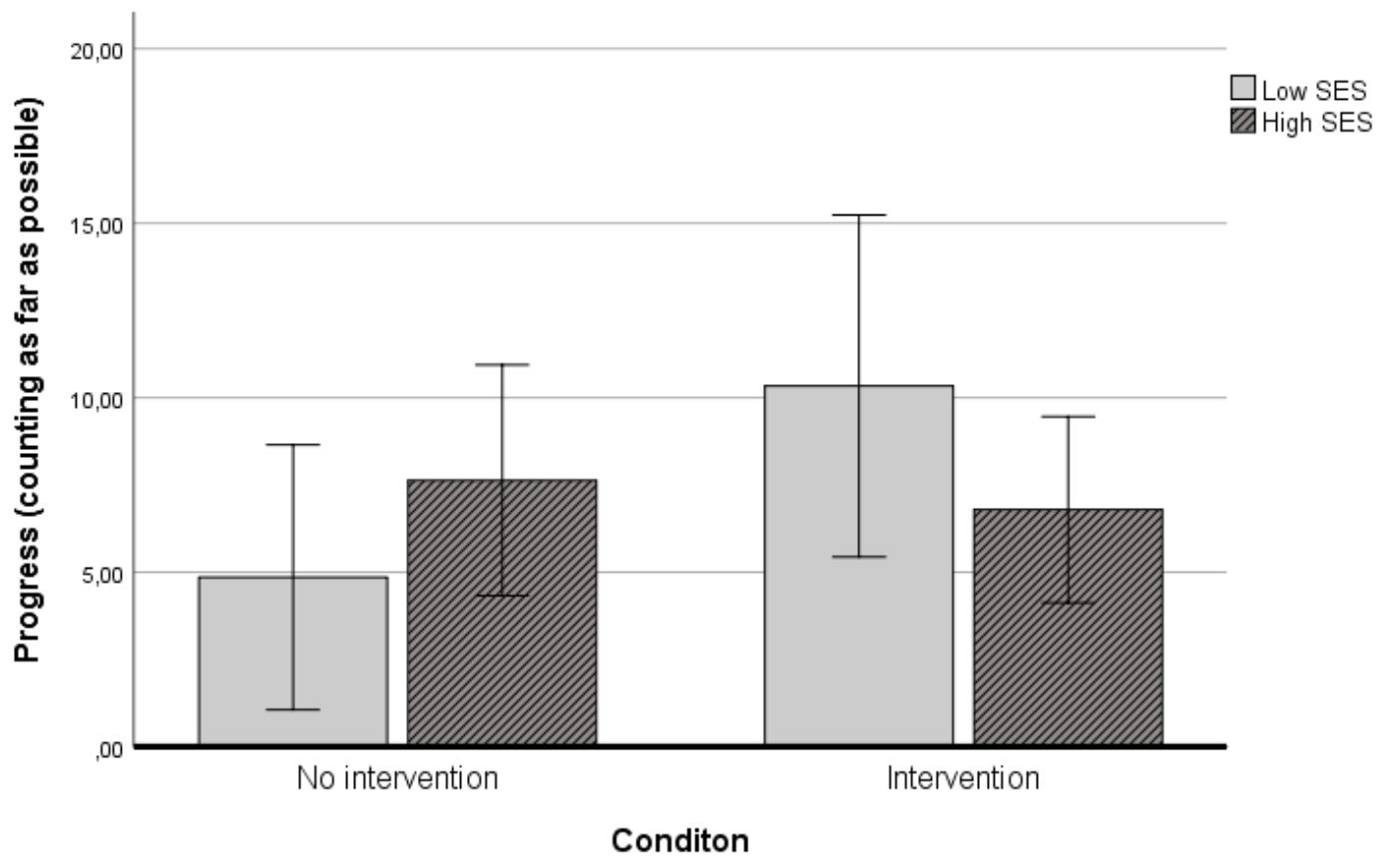

Figure 1. Progress in counting as far as possible as a function of SES and intervention condition. Error bars represent 95\% confidence intervals.

\section{Counting from...}

None of the main effects was significant, with all $F_{\mathrm{S}}<1.105, p>.30$. The expected interaction between SES and intervention was not significant but marginal, $F(1,110)=3.119$, $p=.080, \eta_{p}{ }^{2}=.028[-0.78,0.05]$, as represented in Figure 2. Although the simple effect of intervention was not significant for either low-, $t(110)=1.443, p=.152$, or high-SES children, $t(110)=1.018, p=.311$, it tended to be more positive for the former than for the latter.

It is worth noting that the interaction between intervention and level was significant: $F(1,110)=7.255, p=.008, \eta_{p}{ }^{2}=.062[0.15,0.97]$. Indeed, the intervention condition brought about greater improvement than the control condition only for the children in the second year, $t(110)=2.561, p=.012$. It was not significant for those in the first year, $t(110)=1.361, p$ $=.176$. None of the other effects reached significance, with all $F_{\mathrm{S}}<1.105, p>.295$. 


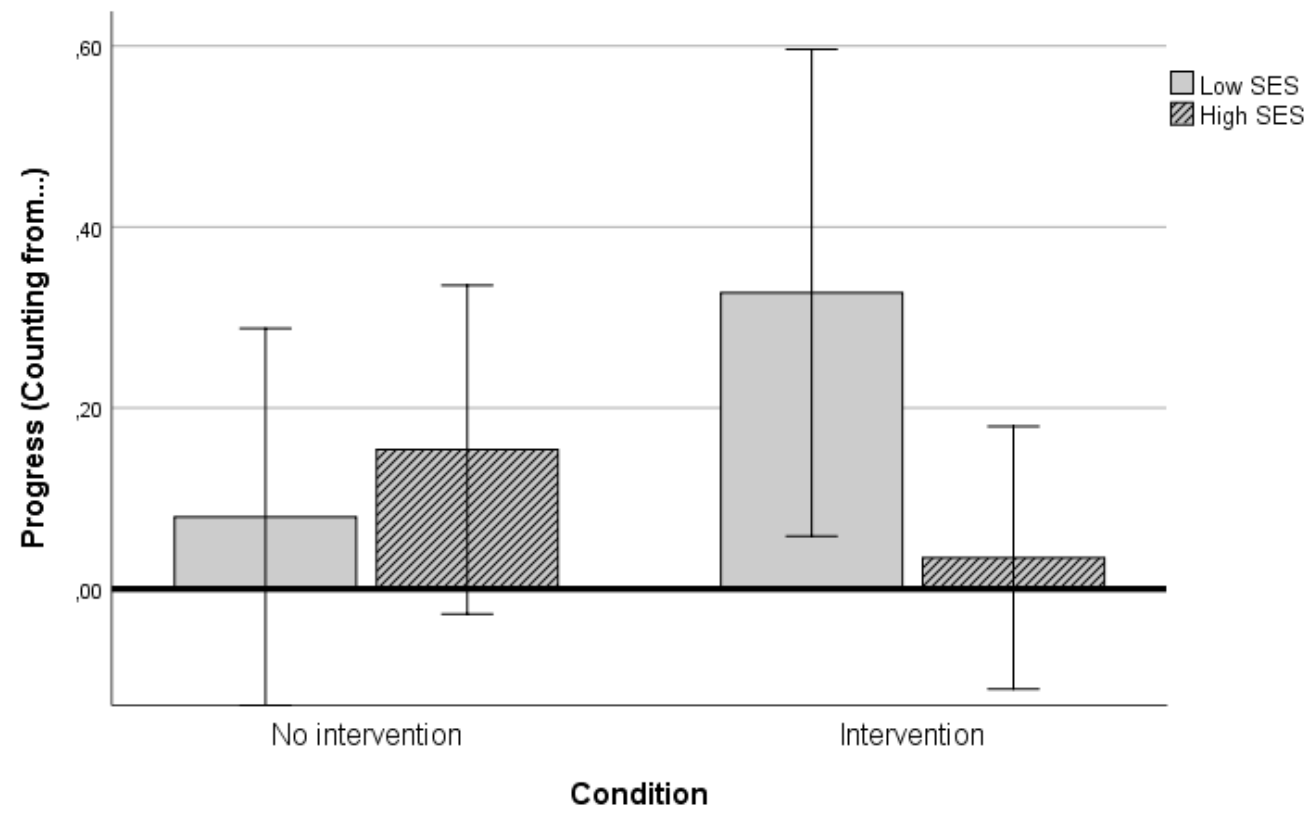

Figure 2. Progress in counting from (a given number) as a function of SES and intervention condition. Error bars represent 95\% confidence intervals.

\section{Cardinality}

\section{The "How Many" Task}

Contrary to expectations, the main effect of intervention and the interaction between SES and intervention were not significant $(F s<1)$. The only significant effect was the interaction between SES and level, $F(1,110)=4.440, p=.037, \eta_{p}{ }^{2}=.039[-3.79,-0.12]$, suggesting that the SES gap (in favor of low-SES children) was greater in the second year, $t(110)=2.422, p=$ .017 , than in the first year, $t(110)<1$.

\section{The "Give n" Task}

A marginal positive main effect of intervention, $F(1,110)=3.382, p=.069, \eta_{p}{ }^{2}=.030[-0.06$, 1.71], indicated that the children in the intervention group tended to improve more $(M=$ 1.914; $S E=0.331)$ than those in the control group $(M=1.093 ; S E=0.299)$. The expected interaction between intervention and SES did not reach significance: $F(1,110)=1.892, p$ $=.172, \mathrm{n}_{\mathrm{p}}{ }^{2}=.017[-2.99,0.54]$. However, it was in the expected direction (cf. Figure 3 ).

Simple slopes suggest that the intervention group tended to progress more than the control 
group for lower-SES, $t(110)=1.947, p=.054$, but not higher-SES children, $t(110)<1$. It is worth noting that the main effect of level was significant, $F(1,110)=3.975, p=.049, \eta_{p}{ }^{2}=$ $.035[-1.77,-0.01]$, indicating that children in the first year $(M=1.949 ; S E=0.341)$ progressed significantly more than those in the second year $(M=1.059 ; S E=0.288)$. No other effect reached significance, with all $F \mathrm{~s}<2.505, p>.11$.

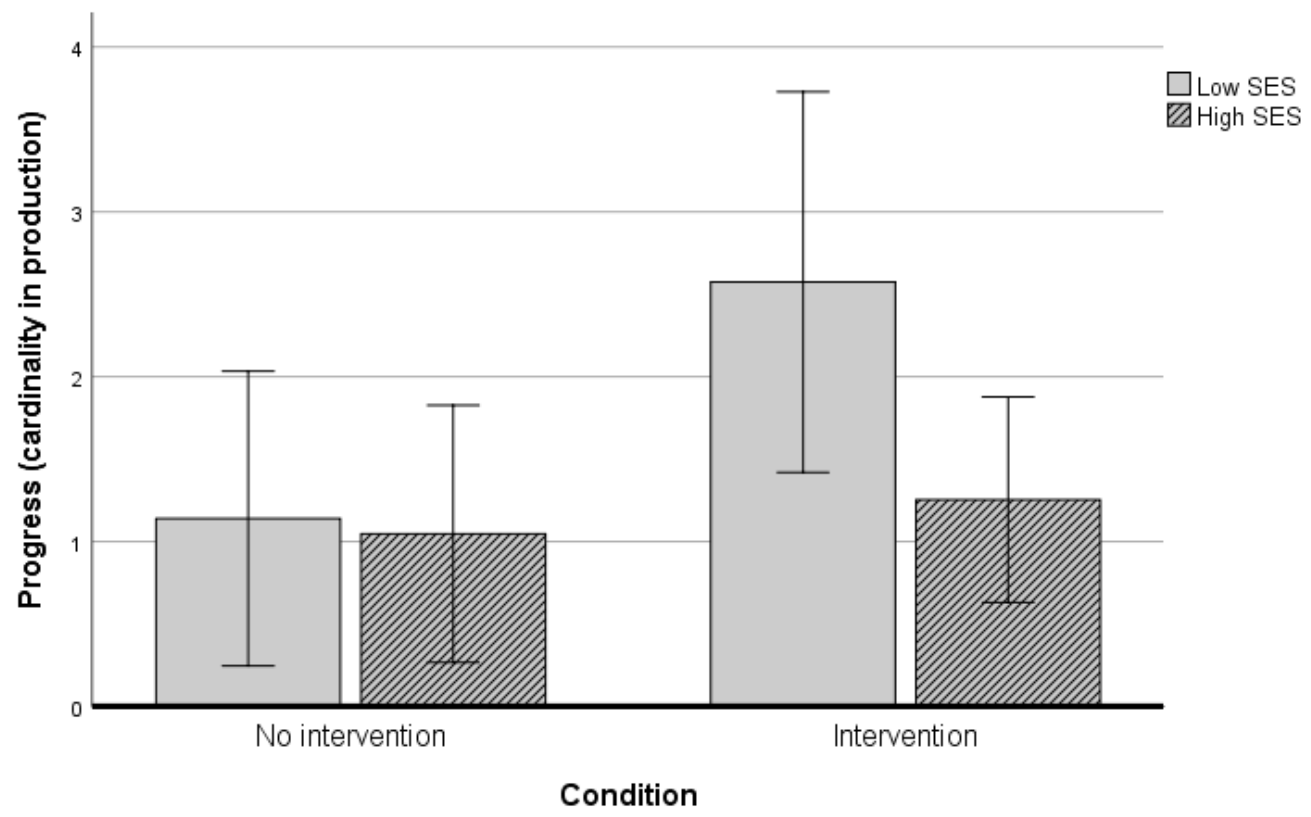

Figure 3. Progress in cardinality through the "give $n$ " task as a function of SES and intervention condition. Error bars represent 95\% confidence intervals.

\section{Term-to-term correspondence}

The intervention did not significantly affect the improvement on the correspondence score ( $F$ $<1)$. The expected SES * intervention interaction was also not significant: $F(1,110)=2.375$, $p=.126$. The analyses only revealed a main effect of SES, $F(1,110)=6.081, p=.015, \eta_{p}{ }^{2}=$ $.052[-2.64,-0.29]$, with the low-SES children $(M=2.830 ; S E=0.490)$ improving more than the high-SES children $(M=1.365 ; S E=0.335)$, and a large main effect of level, $F(1,110)=$ $22.862, p<.001, \eta_{p}{ }^{2}=.172[-4.01,-1.66]$, indicating that the children in the first year $(M=$ $3.517 ; S E=0,453)$ progressed more than those in the second year $(M=.678 ; S E=0.384)$. Interestingly, the interaction between SES and level was once again not significant but 
marginal, $F(1,110)=2.846, p=.094, \eta_{p}{ }^{2}=.025[-0.35,4.36]$, suggesting that the SES gap (in favor of low-SES children) was greater for children in the first year, $t(110)=2.721, p=$ .008 , than the second year, $t(110)<1$.

\section{Arithmetic}

The main effect of the intervention was in the expected direction, although only marginal: $F$ $(1,110)=3.804, p=.054, \eta_{p}^{2}=0.033[-0.01,0.82]$. The children in the intervention group $(M$ $=0.563 ; S E=0.155)$ tended to improve more than those in the control group $(M=.156 ; S E=$ 0.14). Contrary to the predictions, the interaction between intervention and SES was not significant: $F(1,110)=1.174, p=.281$. None of the other effects reached significance $(F<$ 1.54). 
Table 1

Mean score at the pre and the post-test and mean progress as a function of socioeconomic status (SES) and intervention condition

\begin{tabular}{|c|c|c|c|c|c|c|c|c|c|c|c|c|c|}
\hline & & \multicolumn{5}{|c|}{ Intervention group } & \multicolumn{6}{|c|}{ Control group } & \\
\hline & & \multicolumn{3}{|l|}{$\begin{array}{l}\text { Low SES } \\
(N=16)\end{array}$} & \multicolumn{2}{|c|}{$\begin{array}{l}\text { High SES } \\
(N=48)\end{array}$} & \multicolumn{3}{|c|}{$\begin{array}{l}\text { Low SES } \\
(N=23)\end{array}$} & \multicolumn{3}{|c|}{$\begin{array}{l}\text { High SES } \\
(N=31)\end{array}$} & \multirow[b]{2}{*}{ Progress } \\
\hline & & Pre & Post & Progress & Pre & Post & Progress & Pre & Post & Progress & Pre & Post & \\
\hline Numerical & As far as & 9.173 & 19.609 & 10.336 & 9.537 & 16.331 & 6.792 & 9.383 & 14.239 & 4.856 & 13.468 & 21.103 & 7.635 \\
\hline \multirow[t]{3}{*}{ Sequence } & possible & $(2.319)$ & $(3.072)$ & (2.473) & $(1.251)$ & $(1.671)$ & $(1.345)$ & (1.794) & (2.378) & (1.914) & $(1.565)$ & $(2.073)$ & $(1.669)$ \\
\hline & From... & 0.373 & 0.70 & 0.327 & 0.431 & 0.466 & 0.033 & 0.492 & 0.572 & 0.080 & 0.476 & 0.63 & 0.154 \\
\hline & & $(0.116)$ & $(0.108)$ & $(0.136)$ & $(0.063)$ & $(0.058)$ & $(0.074)$ & $(0.09)$ & $(0.083)$ & $(0.106)$ & $(0.078)$ & $(0.073)$ & $(0.092)$ \\
\hline \multirow[t]{6}{*}{ Cardinality } & How many & 7.242 & 8.675 & 1.434 & 7.712 & 8.645 & 1.032 & 6.674 & 7.972 & 1.298 & 7.447 & 8.298 & 0.851 \\
\hline & & $(0.696)$ & $(0.59)$ & $(0.592)$ & $(0.376)$ & $(0.319)$ & $(0.322)$ & $(0.539)$ & $(0.457)$ & $(0.458)$ & $(0.47)$ & $(0.398)$ & (0.399) \\
\hline & Give $n$ & 4.992 & 7.566 & 2.574 & 6.346 & 7.6 & 1.284 & 5.562 & 6.701 & 1.140 & 6.460 & 7.507 & 1.047 \\
\hline & & $(0.679)$ & $(0.66)$ & $(0.584)$ & $(0.366)$ & $(0.356)$ & $(0.318)$ & $(0.525)$ & $(0.511)$ & $(0.452)$ & $(0.458)$ & $(0.445)$ & (0.394) \\
\hline & Correspondence & 6.205 & 9.439 & 3.235 & 7.299 & 8.155 & 0.879 & 5.114 & 7.538 & 2.424 & 7.03 & 8.905 & 1.875 \\
\hline & term to term & $(0.788)$ & $(0.728)$ & (0.778) & $(0.425)$ & $(0.393)$ & $(0.423)$ & $(0.61)$ & $(0.563)$ & $(0.602)$ & $(0.532)$ & $(0.491)$ & $(0.525)$ \\
\hline
\end{tabular}




\begin{tabular}{lllllllllllllll}
\hline Arithmetic & 1.527 & 2.191 & 0.664 & 1.754 & 2.217 & 0.449 & 1.886 & 1.917 & 0.030 & 2.083 & 2.365 & 0.282 & \\
& $(0.251)$ & $(0.238)$ & $(0.273)$ & $(0.135)$ & $(0.129)$ & $(0.149)$ & $(0.194)$ & $(0.184)$ & $(0.211)$ & $(0.169)$ & $(0.161)$ & $(0.184)$ & \\
\hline
\end{tabular}




\section{Discussion}

\section{Summary of the Findings}

The purpose of the present study was to test the effect of an early mathematical intervention on kindergarteners' progress in acquiring basic mathematical skills. It was argued that the regular practice of activities involving cardinality, ordinality, and numerical transformations should improve or accelerate these acquisitions, leading to an increasing mastery of specific skills like the verbal numerical sequence, abstraction of the notion of cardinality, and ability to compute arithmetic transformations. In addition, because they are less likely to practice similar activities at home (Saxe et al., 1987), and in line with recent findings showing that the effect sizes of early interventions were larger for low- than for high-SES students (Nelson \& McMaster, 2019; see also Jordan \& Levine, 2009), the intervention should prove more efficient for low- than for high-SES children. It is worth noting that, in the present study, lowSES children were not only the target of the intervention; they were also compared to higherSES children. The effects of this intervention were tested in a randomized, ecological, real classroom experiment. Indeed, all the teachers involved in this research were enrolled in a theoretical mathematical training, and only half of them implemented the intervention before the posttest. The other half agreed not to change their teaching practices before the posttest (i.e., business-as-usual approach). Thus, in the present research, the teachers in the experimental group and the control group were highly comparable in their knowledge of mathematical concepts or their motivation to improve their teaching practices. This created ideal conditions for testing the "mere" effect of the intervention (Connolly et al., 2018).

The results revealed mixed findings, although — overall and even if the effect sizes are relatively small — they tended to confirm the effectiveness of the intervention, especially in terms of verbal numerical sequence and arithmetic skills. As expected, the intervention seemed to accelerate progress on the verbal numerical sequence, particularly among lower- 
SES children. In addition, all the children progressed on the "give $n$ " task and arithmetic, but the improvement was greater in the intervention condition than in the control group, supporting the idea that the present intervention could accelerate children's progress in their acquisition of these mathematical concepts. These results are in line with previous research showing that early mathematical skills can significantly improve with specific interventions at the kindergarten level (e.g., Lewis Presser et al., 2015; Clement \& Sarama, 2008), particularly when the interventions focus on abilities likely to develop during that preschool period (i.e., cardinality and transformation).

\section{Limitations and Perspectives}

The intervention tended to benefit the lower-SES children more than the higher-SES children, at least with regard to the verbal numerical sequence, which is consistent with previous research showing that children who benefit the most from early interventions seem to be those who need it the most (Clements et al., 2020; Galindo \& Sonnenschein, 2015; Nelson \& McMaster, 2019; Starkey et al., 2004). However, the question of whether the intervention leads to greater improvement in low- rather than high-SES children remains unresolved. Indeed, the interaction between SES and intervention was only observed in the verbal numerical sequence even though it was in the expected direction for the other measures. One cannot exclude that a ceiling effect might have occurred on most of the dependent variables. Moreover, this inconsistency can be explained by the fact that the sample was not as heterogeneous as expected in terms of SES. Indeed, relatively few children were categorized as being low-SES children based on an a priori classification. This small low-SES sample size, together with the uneven distribution of high- and low-SES children, makes it relatively difficult to interpret differences between these groups. In addition, as mentioned earlier, the present data are not independent (the intervention took place at a classlevel) but the present experiment was not powered enough to use Hierarchical Linear 
Modelling. Thus, even if the present results are encouraging regarding the potential of the intervention to reduce the SES-related mathematics achievement gap, more research is needed to draw conclusions on this issue. Therfore, the present results should be replicated in larger samples that are more balanced in terms of SES.

In addition, although the intervention tended to accelerate improvement in some skills (verbal numerical sequence, give $n$ task, and arithmetic) compared to the control condition, in others (cardinality in designation and term-to-term correspondence), the improvement in the control group and the intervention group was similar. The lack of findings on these measures, as well as the fact that most of the expected effects were only marginal, can probably partially be explained by the nature of the design. Indeed, all the teachers involved in this study (control and experimental groups) were trained by an expert in numeracy, which made the two groups highly comparable — a clear advantage at the methodological level. However, although the teachers randomly assigned to the control group agreed not to change their teaching practices, the possibility that the theoretical training they received affected the way they taught mathematics cannot be excluded. This could explain why the children in the two groups progressed to a similar extent on some measures. In other words, the randomization and the high comparability between the two groups of children undeniably constitute methodological strengths of the present research. However, they could also have reduced the strength of the expected effects, as well as the probability of these effects reaching the level of significance. In support of these arguments, meta-analyses testing the effects of various interventions indicate that effect sizes are usually smaller in research using randomized groups than in research using quasi-experimental designs (Lazowski \& Hulleman, 2015). Relatedly, it is worth noting that working on the three key abilities (verbal numerical sequence, cardinality and arithmetic transformation) was part of the program in kindergarten. For this reason, we assume that the difference between the experimental condition and the 
control group did not stand in the dosage in addressing the three key abilities but in the way they were addressed. However, control group was a business-as-usual condition and fidelity was not measured in the experimental condition. Therefore, one cannot make sure practices really differed across the two groups, while time spent on each key concept was maintained constant. In future research, standardized observation within classes should take place to quantify precisely the differences and similarities between the two conditions.

\section{Implications for Practice}

Despite these limitations, the results of the present research are highly encouraging. Indeed, although they should be replicated on larger samples, these results document that a 5week intervention based on cardinality and arithmetic transformation activities can significantly accelerate the progress of kindergarten children, particularly in arithmetic. Arithmetic is indeed a fundamental dimension and one that has been shown to be especially predictive of later performances in both mathematics and literacy (Duncan et al., 2007). Thus, the present results support recent research showing that early interventions are particularly efficient for increasing children mathematical knowledge and consequently, should be promoted in kindergarten classrooms (Clements \& Sarama, 2011; Raudenbush et al., 2020). Indeed, mathematical skills are built on the basis of many formal but also informal experiences (Ginsburg, 1977). Therefore, depending on home practices, children do not all have equal opportunities to develop these skills (Levine et al., 2010) as early as 3 or 4 years old, with further implication on later achievement in arithmetic (Arnold \& Doctoroff, 2003). For this reason, it is particularly important to promote such interventions in the classroom, in order to provide opportunities for all children to progress in mathematics. Research supports that interventions designed to accelerate mathematical progress in preschool years have a positive effect on these children's mathematical trajectories even many years thereafter (Clements \& Sarama, 2011; Jordan et al., 2009). Some other interventions targeting preschool 
children already exist (Lilliard \& Else-Quest, 2006; Nelson \& McMaster, 2019; Siegler \& Ramani, 2008) but it is important to identify several of them, to ensure diversity in the classroom, with related benefits for progress (Clements et al., 2020). The present research has tested one of these interventions and, as such, we believe it importantly contributes to providing relevant and evidence-based tools, which may be particularly useful for kindergarten teachers wishing to improve their practice.

\section{Data Availability Statement}

The data and materials from the present study are openly available on: osf.io/ktp4v. 


\section{References}

Arnold, D. H., \& Doctoroff, G. L. (2003). The early education of socioeconomically disadvantaged children. Annual Review of Psychology, 54(1), 517-545. doi: 10.1146/annurev.psych.54.111301.145442.

Benoit, L., Lehalle, H., Molina, M., Tijus, C., \& Jouen, F. (2013). Young children's mapping between arrays, number words, and digits. Cognition, 129(1), 95-101. https://doi.org/https://doi.org/10.1016/j.cognition.2013.06.005

Blevins-Knabe, B., \& Musun-Miller, L. (1996). Number use at home by children and their parents and its relationship to early mathematical performance. Early Development and Parenting, 5(1), 35-45. doi:10.1002/(SICI)1099-0917(199603)5:1<35::AIDEDP113>3.0.CO;2-0

Casey, B. M., Lombardi, C. M., Thomson, D., Nguyen, H. N., Paz, M., Theriault, C. A., \& Dearing, E. (2018). Maternal support of children's early numerical concept learning predicts preschool and first-grade math achievement. Child Development, 89(1), 156173. doi: $10.1111 /$ cdev.12676.

Chu, F.W., vanMarle, K., \& Geary, D.C. (2015). Early numerical foundations of young children's mathematical development. Journal of Experimental Child Psychology, 132, 205-212. https://doi.org/10.1016/j.jecp.2015.01.006

Clements, D. H., Dumas, D., Dong, Y., Banse, H. W., Sarama, J., \& Day-Hess, C. A. (2020). Strategy diversity in early mathematics classrooms. Contemporary Educational Psychology, 60. doi: 10.1016/j.cedpsych.2019.101834

Clements, D., \& Sarama, J. (2008). Experimental evaluation of the effects of a research-based preschool mathematics curriculum. American Educational Research Journal, 45(2), 443-494. doi: 10.3102/0002831207312908 
Clements, D., \& Sarama, J. (2011). Early childhood mathematics intervention. Science, 333(6045), 968-970. doi 10.1126/science.1204537

Colomé, A., \& Noël, M-P. (2012). One first? Acquisition of the cardinal and ordinal uses of numbers in preschoolers. Journal of Experimental Child Psychology, 113(2), 233-247. https://doi.org/10.1016/j.jecp.2012.03.005

Condry, K.F., \& Spelke, E.S. (2008). The development of language and abstract concepts: The case of natural number. Journal of Experimental Psychology: General, 137(1), 22-38. doi: 10.1037/0096-3445.137.1.22.

Connolly, P., Keenan, C., \& Urbanska, K. (2018). The trials of evidence-based practice in education: a systematic review of randomised controlled trials in education research 1980-2016. Educational Research, 60(3), 276-291. https://doi.org/10.1080/00131881.2018.1493353

Davidson, K., Eng, K., \& Barner, D. (2012). Does learning to count involve a semantic induction? Cognition, 123(1), 162-173. doi:10.1016/j.cognition.2011.12.013

Duncan, G.J., Dowsett, C.J., Claessens, A., Magnuson, K., Huston, A.C., Klebanov, P., Pagani, L.S., Feinstein, L., Engel, M., Brooks-Gunn, J., Sexton, H., Duckworth, K., \& Japel, C. (2007). School readiness and later achievement. Developmental Psychology, 43(6), 1428-1446. doi: 10.1037/0012-1649.43.6.1428.

Authors et al. (2017).

Author (2018).

Feigenson, L., Carey, S., \& Spelke, E. (2002). Infants' discrimination of number vs. continuous extent. Cognitive Psychology, 44(1), 33-66. https://doi.org/https://doi.org/10.1006/cogp.2001.0760 
Frye, D., Baroody, A. J., Burchinal, M., Carver, S. M., Jordan, N. C., McDowell, J. (2013). Teaching math to young children: A practice guide. National Center for Education and Regional Assistance, Institute of Education Sciences, U.S. Department of Education.

Fuson, K. C. (1988). Children's counting and concepts of number. Springer-Verlag.

Galindo, C., \& Sonnenschein, S. (2015). Decreasing the SES math achievement gap: Initial math proficiency and home learning environments. Contemporary Educational Psychology, 43, 25-38. https://doi.org/10.1016/j.cedpsych.2015.08.003

Geary, D.C. \& van Marle, K. (2018). Growth of symbolic number knowledge accelerates after children understand cardinality. Cognition, 177, 69-78. doi.org/10.1016/j.cognition.2018.04.002

Ginsburg, H. (1977). The psychology of arithmetic thinking. Journal of Children's Mathematical Behavior, 1(4), 1-89.

Huttenlocher, J., Jordan, N. C., \& Levine, S. C. (1994). A mental model for early arithmetic. Journal of Experimental Psychology: General, 123(3), 284-296. http://dx.doi.org/10.1037/0096-3445.123.3.284

Jordan, N. C., Glutting, J., Dyson, N., Hassinger-Das, B., \& Irwin, C. (2012). Building Kindergartners' number sense: A randomized controlled study. Journal of Educational Psychology, 104(3), 647-660. doi: 10.1037/a0029018

Jordan, N. C., Huttenlocher, J., \& Levine, S. C. (1992). Differential calculation abilities in young children from middle- and low-income families. Developmental Psychology, 28(4), 644-653. http://dx.doi.org/10.1037/0012-1649.28.4.644

Jordan, N.C., Kaplan, D., Ramineni, C., \& Locuniak, M.N. (2009). Early math matters: Kindergarten number competence and later mathematics outcome. Developmental Psychology, 45(3), 850-867. doi: 10.1037/a0014939 
Jordan, N. C., \& Levine, S. C. (2009). Socioeconomic variation, number competence, and mathematics learning difficulties in young children. Developmental Disabilities Research Reviews, 15(1), 60-68. doi: 10.1002/ddrr.46

Jordan, N. C., Levine, S. C., \& Huttenlocher, J. (1994). Development of calculation abilities in middle- and low-income children after formal instruction in school. Journal of Applied Developmental Psychology, 15(2), 223-240. https://doi.org/https://doi.org/10.1016/0193-3973(94)90014-0

Klein, J. S., \& Bisanz, J. (2000). Preschoolers doing arithmetic: The concepts are willing but the working memory is weak. Canadian Journal of Experimental Psychology, 54(2), 105-116. http://dx.doi.org/10.1037/h0087333

Knudsen, B., Fischer, M.H., Henning² A., \& Aschersleben, G. (2015). The development of arabic digit knowledge in 4- to 7-year-old children. Journal of Numerical Cognition, 1(1), 21-37. doi:10.5964/jnc.v1i1.4

Lazowski, R. A., \& Hulleman, C. S. (2015). Motivation interventions in education: A metaanalysis. Review of Educational Research, 66(2), 602-640.

Le Corre, M., Van de Walle, G., Brannon, E. M., \& Carey, S. (2006). Re-visiting the competence/performance debate in the acquisition of the counting principles. Cognitive Psychology, 52(2), 130-169. https://doi.org/https://doi.org/10.1016/j.cogpsych.2005.07.002

LeFevre, J., Polyzoi, E., Skwarchuk, S., Fast, L., \& Sowinski, C. (2010). Do home numeracy and literacy practices of Greek and Canadian parents predict the numeracy skills of kindergarten children? International Journal of Early Years Education, 18(1), 55-70. https://doi.org/10.1080/09669761003693926

LeFevre, J.-A., Skwarchuk, S.-L., Smith-Chant, B. L., Fast, L., Kamawar, D., \& Bisanz, J. (2009). Home numeracy experiences and children's math performance in the early 
school years. Canadian Journal of Behavioural Science / Revue Canadienne Des Sciences du Comportement, 41(2), 55-66. http://dx.doi.org/10.1037/a0014532

Levine, S. C., Jordan, N. C., \& Huttenlocher, J. (1992). Development of calculation abilities in young children. Journal of Experimental Child Psychology, 53(1), 72-103. https://doi.org/https://doi.org/10.1016/S0022-0965(05)80005-0

Levine, S.C, Suriyakham, L.W., Rowe, M.L., Huttenlocher, J., \& Gunderson, E.A. (2010). What counts in the development of young children's number knowledge? Developmental Psychology, 46(5),1309-1319. doi: 10.1037/a0019671.

Lewis Presser, A.L., Clements, M., Ginsburg, H., \& Ertle, B. (2015). Big math for little kids: The effectiveness of a preschool and kindergarten mathematics curriculum. Early Education and Development, 26(3), 399-426. Doi10.1080/10409289.2015.994451

Lillard, A., \& Else-Quest, N. (2006). Evaluating Montessori education. Science, 313(5795), 1893-1894. https://doi.org/10.1126/science.1132362

Lyons, I. M., \& Beilock, S. L. (2011). Numerical ordering ability mediates the relation between number-sense and arithmetic competence. Cognition, 121(2), 256-261. https://doi.org/https://doi.org/10.1016/j.cognition.2011.07.009

Lyons, I. M., Price, G. R., Vaessen, A., Blomert, L., \& Ansari, D. (2014). Numerical predictors of arithmetic success in grades 1-6. Developmental Science, 17(5), 714-726. doi:10.1111/desc.12152

Lyons, I. M., Vogel, S. E., \& Ansari, D. (2016). Chapter 8 - On the ordinality of numbers: A review of neural and behavioral studies. In M. Cappelletti \& W. Fias (Eds.), The mathematical brain across the lifespan (Vol. 227, pp. 187-221). London: Elsevier. https://doi.org/https://doi.org/10.1016/bs.pbr.2016.04.010 
Maas, C. J. M., \& Hox, J. (2005). Sufficient Sample Sizes for Multilevel Modeling. Methodology. European Journal of Research Methods for the Behavioral and Social Sciences, 1(3), 8692.

Mix, K.S. (2008). Children's equivalence judgments: Crossmapping effects. Cognitive Development, 23(1), 191-203. doi: 10.1016/j.cogdev.2007.03.001

Mix, K.S., Huttenlocher, J., \& Levine, S.C. (2002). Multiple cues for quantification in infancy: is number one of them? Psychological Bulletin, 128(2), 278-94. http://dx.doi.org/10.1037/0033-2909.128.2.278

Melhuish, E. C., Sylva, K., Sammons, P., Siraj-Blatchford, I., Taggart, B., Phan, M. B., \& Malin, A. (2008). Preschool influences on mathematics achievement. Science, 321(5893), 1161-1162. https://doi.org/10.1126/science.1158808

Nelson, G., \& McMaster, K. L. (2019). The effects of early numeracy interventions for students in preschool and early elementary: A meta-analysis. Journal of Educational Psychology, 111(6), 1001-1022. https://doi.org/http://dx.doi.org/10.1037/edu0000334

Pagani, L.S., Fitzpatrick, C., Archambault, I., \& Janosz, M. (2010). School readiness and later achievement: A French Canadian replication and extension. Developmental Psychology, 46(5), 984-994. doi: 10.1037/a0018881

Ramani, G.B., \& Siegler, R.S. (2011). Reducing the gap in numerical knowledge between low- and middle-income preschoolers. Journal of Applied Developmental Psychology, 32(3), 146-159. https://doi.org/10.1016/j.appdev.2011.02.005

Rasmussen, C., \& Bisanz, J. (2005). Representation and working memory in early arithmetic. Journal of Experimental Child Psychology, 91(2), 137-157. https://doi.org/https://doi.org/10.1016/j.jecp.2005.01.004

Raudenbush, S. W., Hernandez, M., Goldin-Meadow, S., Carrazza, C., Foley, A., Leslie, D., Sorkin, J. E., \& Levine, S. C. (2020). Longitudinally adaptive assessment and 
instruction increase numerical skills of preschool children. Proceedings of the National Academy of Sciences, 117(45), 27945 LP - 27953.

https://doi.org/10.1073/pnas.2002883117

Rubinsten, O., \& Sury, D. (2011). Processing ordinality and quantity: The case of developmental dyscalculia. PloS one, 6(9). https://doi.org/10.1371/journal.pone.0024079

Sarnecka, B. W., \& Carey, S. (2008). How counting represents number: What children must learn and when they learn it. Cognition, 108(3), 662-674. https://doi.org/https://doi.org/10.1016/j.cognition.2008.05.007

Sasanguie, D., \& Vos, H. (2018). About why there is a shift from cardinal to ordinal processing in the association between first and second grade. Developmental Science, 21(5). https://doi.org/10.1111/desc.12653

Saxe, G., Guberman, S., Gearhart, M., Gelman, R., Massey, C., \& Rogoff, B. (1987). Social processes in early number development. Monographs of the Society for Research in Child Development, 52(2), 1-162. doi:10.2307/1166071.

Siegler, R.S., \& Ramani, G.B. (2008). Playing linear numerical board games promotes lowincome children's numerical development. Developmental Science, 11(5), 655-661.

Siegler, R.S., \& Shrager, J. (1984). Strategy choices in addition and subtraction: How do children know what to do? In C. Sophian (Ed.), The origins of cognitive skills (pp. 229 - 293). Erlbaum.

Authors et al. (2013).

Starkey, P., \& Cooper, R. G. (1995). The development of subitizing in young children. British Journal of Developmental Psychology, 13(4), 399-420. doi:10.1111/j.2044835X.1995.tb00688.x 
Starkey, P., Klein, A., \& Wakeley, A. (2004). Enhancing young children's mathematical knowledge through a pre-kindergarten mathematics intervention. Early Childhood Research Quarterly, 19(1), 99-120. https://doi.org/10.1016/j.ecresq.2004.01.002

Starkey, P., \& Klein, A. (2000). Fostering parental support for children's mathematical development: An intervention with head start families. Early Education and Development, 11(5), 659-680. https://doi.org/10.1207/s15566935eed1105_7

Stipek, D.J., \& Ryan, R.H. (1997). Economically disadvantaged preschoolers: Ready to learn but further to go. Developmental Psychology, 33(4), 711-723. http://dx.doi.org/10.1037/0012-1649.33.4.711

Wiese, H. (2003). Numbers, language, and the human mind. Cambridge University Press. doi:10.1017/CBO9780511486562 